\title{
ANTIMICROBIAL ACTIVITY OF LEMON PEEL (CITRUS LIMON) EXTRACT
}

\author{
JUNAB ALI*, BISWAJIT DAS, TRIDEEP SAIKIA \\ Girijananda Chowdhury Institute of Pharmaceutical Science, Azara, Guwahati 781017 \\ Email: junab.gips@gmail.com
}

Received: 27 Jan 2017, Revised and Accepted: 20 Apr 2017

\begin{abstract}
Objective: To evaluate the antimicrobial activity of methanolic extract from the peel of the fruit of Citrus Limon (Family-Rutaceae) in conjugation with phytochemical analysis.

Methods: The methanolic extract from the peel of the fruit of Citrus Limon (Family-Rutaceae) was separated from fruits, shade dried, powdered and extracted using methanol, analysed for phytochemical constituents using standard methods. The antimicrobial activity of the plant extract was examined against 2 bacterial strains among one is Gram-positive (Staphylococcus aureus) and other is Gram-negative (Escherichia coli) and 1 fungal strains (Candida albicans) using agar well diffusion method.
\end{abstract}

Results: The present investigation shows the phytochemical analysis, antimicrobial activity of the methanolic extract of the fruits peel Citrus limon Various phytochemical analyses revealed the presence of alkaloids, saponin, flavonoids, carbohydrates, glycosides and citric acids and tannins. The antimicrobial activity of the methanolic extract of the plant showed significant result against all the of the test organisms.

Conclusion: The present study concluded that methanolic extract of the peel of Citrus Limon contains the high presence of phytochemicals. The methanolic extract of the plant was found to possess promising antimicrobial activity when compared with the standards.

Keywords: Citrus Limon, Antimicrobial, Zone of Inhibition, Agar disc diffusion method

(C) 2017 The Authors. Published by Innovare Academic Sciences Pvt Ltd. This is an open access article under the CC BY license (http://creativecommons.org/licenses/by/4.0/) DOI: http://dx.doi.org/10.22159/ijcpr.2017v9i4.20962

\section{INTRODUCTION}

For a long period of time, there are many naturally occurring materials which are having biologically active substance and show biological activity for the health of human beings and they have a great potential for producing new drugs. In plant chemotherapy, the use of naturally occurring antimicrobial substances is gaining more importance and have higher significant values [1]

According to WHO medicinal plants are used in order to the therapeutic purpose and be used as a pioneering the synthesis, semisynthetic chemical drugs [2]. About $80 \%$ of the world population use herbal medicine to treat the ailment. From the statistics, it is under in developed countries and higher in less developed countries [3].

Medicinal plants have an important role for the health of individuals and communities. These plants have a great medicinal value that lies various chemical substances which produce physiological action on the human body. Medicinal plants contains many chemical compounds such as alkaloids, flavonoids, glycosides, saponins, resins, oleoresins, sesquiterpene, phenolic compounds, fats and oils [4].

Citrus fruit is an important medicinal plant of the family Rutaceae. It is used mainly for its alkaloids, which are having anticancer activities and the antibacterial potential in crude extracts of different parts (leaves, stem, root, juice, peel and flower) of lemon against various bacterial strains. Citrus fruits have a broad spectrum of biological activity including antibacterial, antifungal, antidiabetic, anticancer and antiviral activities due to alkaloids [5]

The lemon peel extracts is done by different solvents such as ethanol, methanol and acetone which are subjected to antibacterial assay. Methanolic extract shows higher antimicrobial activity against tested microorganisms (E. coli, S. aureus, Candida albicans and Trichophyton rubrum.) [6].

The citrus peels are rich in nutrients and contain many phytochemicals, these are $\beta$ and $\gamma$-sitosterol, glycosides and volatile oils. Some polyethoxylated, phenolic compound, ascorbic acid, flavones have several important activities, which are very rare in other plants. Citrus peels also used in scurvy, digestion, respiratory disorders, peptic ulcer, eye infections, gums, gout, skin care, piles, urinary disorders, weight loss traditionally. In addition, it also used in disinfect and sterilizing reagent. So the target of this present study is to identify the phytochemical components of Citrus limon and to determine the antimicrobial effects of the dried peel extract on $E$ coli, S. aureus, Candida albicans and Trichophyton rubrum.

\section{MATERIALS AND METHODS}

\section{Collection of plant materials}

Citrus limon was collected from Azara market, Guwahati India. The plant specimen was authenticated by Dr. G. C. Sarma, Curator, Department of Botany, Gauhati University, Assam. The voucher specimen has been deposited in the Herbarium of the Department of Botany, Gauhati University with voucher no Acc. No.-18219 dated 28-10-2016 for future reference.

\section{Chemicals and reagents}

Methanol, Ethanol, Petroleum Ether(PE), Chloroform, hydrochloric acid, Dragondorff reagent, Mayer's reagent, Wagner's reagent, Benedict's reagent, sulphuric acid, lead acetate, Molisch's reagent, Fehling solution A and B, sodium citrate, copper sulphate, ferric chloride, sodium hydroxide, glacial acetic acid, benzene, chloroform, ammonia, nitric acid, dimethyl sulfoxide (DMSO), potassium nitrite, gelatine, Beef extract, Peptone, Sodium Chloride, Dextrose and agar. All the chemicals and solvents used were of standard analytical grades.

\section{Preparation of extracts of Citrus lemon peels}

The Citrus lemon peels were dried under shade and then undergone crushing in an electric blender to form powdered. Then it was defatted by Petroleum ether dried the marc again extracted with chloroform then again dried the marc and finally extracted with methanol using Soxhlet's extractor. The percent yield of methanolic extract was then calculated out.

\section{Preparation of extract/drug stock solution}

The stock solution of Citrus limon peel extract was prepared on each occasion by careful weighing and dissolving in a suitable volume of Dimethylsulphoxide (DMSO) to get a concentration of $100 \mathrm{mg} / \mathrm{ml}$. A 
tablet of ciprofloxacin was dissolved in an appropriate volume of water to get $5 \mathrm{mg} / \mathrm{ml}$ of stock solution.

\section{Phytochemical screening}

Phytochemicals screening were done using standard method. All the experiment has been repeated in triplicate for final confirmation of the result.

1. Test for saponins: To $1 \mathrm{ml}$ of aqueous extract was added to few volume of distilled water in a test tube. The solution was shaken vigorously and observed for a stable persistent froth for $20 \mathrm{~min}$.

2. Test for alkaloids: Two methods were used to test for alkaloids. First, evaporate $20 \mathrm{ml}$ of ethanol extract, the dry residue dissolved in $5 \mathrm{ml}$ of $\mathrm{HCl}(2 \mathrm{~N})$ and filtered. A few drops of Mayer's reagent and Wagner was added, the presence of precipitate indicates the alkaloids.

Second, 3 to $15 \mathrm{ml}$ of the aqueous extract was added $2 \mathrm{ml}_{\text {of }} \mathrm{NH}_{4} \mathrm{OH}$ à $10 \%$. The alkaloid was extracted 3 times with $10 \mathrm{ml}$ chloroform. The chloroform layer was washed 3 times with $2 \mathrm{ml}$ of HCL (10\%). This was divided into two portions. Mayer's reagent was added to one portion and Wagner's reagent to the other. The formation of a brown or white precipitate was regarded as positive for the presence of alkaloids.

3. Test for sterols and steroids: Extracts were treated with chloroform and filtered. The filtrates were treated with few drops of Conc. Sulphuric acid, shaken and allowed to stand. Appearance of golden yellow colour indicates the presence of triterpene.

4. Test for the phenolic compounds: Flavonoids: The ethanol extract $5 \mathrm{ml}$ was added to a concentrated sulphuric acid (H2SO4) (1 $\mathrm{ml}$ ) and $0.5 \mathrm{~g}$ of $\mathrm{Mg}$. A pink or red coloration that disappears on standing $3 \mathrm{~min}$. indicates the presence of flavonoids.

5. Tannins: Two methods were used to test for tannins. First, about $1 \mathrm{ml}$ of the ethanol extract was added in $2 \mathrm{ml}$ of water in a test tube. 2 to 3 drops of diluted ferric chloride $\left(\mathrm{Fecl}_{3}\right)$ solution was added and observed for green to blue-green or blue-black coloration. Second, 2 $\mathrm{ml}$ of the aqueous extract was added to $2 \mathrm{ml}$ of water, 1 to 2 drops of diluted ferric chloride (Fecl3) solution were added. A dark green or blue-green coloration indicates the presence of tannins.

6. Test for Glycoside: $2 \mathrm{ml}$ of concentrated $\mathrm{H}_{2} \mathrm{SO}_{4}$ was added carefully and shaken gently. A reddish brown colour indicated the presence of steroidal ring i. an eglycone portion of the glycoside $[13,14]$.

\section{Culture media}

The media employed for the study was solid agar media.

\section{Microbial strains}

Three bacterial strains [Staphyllococcus aureus (ATCC 25923), Escherichia coli (ATCC 25922) and two fungi [Candida albicans (ATCC 10231), and Trichophyton rubrum (ATCC 28188)] were used. Stains were obtained from Girijananda Chowdhury Institute of Pharmaceutical Science, Azara, Guwahati.

\section{Sterilization of materials}

The petri dishes and pipettes packed into metal canisters were appropriately sterilized in the hot air oven at $170{ }^{\circ} \mathrm{C}$ for $1 \mathrm{~h}$ at each occasion. A solution of the extract and culture media were autoclaved at $121^{\circ} \mathrm{C}$ for $15 \mathrm{~min}$.

\section{Antibacterial activity}

The antimicrobial activity of the different extracts of the plant was assayed by agar-well diffusion method as described in NCCLS, 1993 [15]. Petri plates containing $20 \mathrm{ml}$ nutrient agar medium was seeded with bacterial strains. Wells of approximately $10 \mathrm{~mm}$ was bored using a well cutter. Plant extracts were prepared in DMSO (stock: $1 \mathrm{mg} / \mathrm{ml}$ DMSO). The plant extracts of 25,50 , and $100 \mu \mathrm{l}$ concentrations were added. Ciprofloxacin $(20 \mu \mathrm{l})$ and DMSO $(100 \mu \mathrm{l})$ were used as positive and negative controls respectively.

The plates were then incubated at $37{ }^{\circ} \mathrm{C}$ for $24 \mathrm{~h}$. The antimicrobials present in the plant extract are allowed to diffuse out into the medium and interact with the test organisms in the freshly seeded plate. The diameter of the zone of inhibitions was measured in millimetres after $24 \mathrm{~h}$.

\section{Antifungal activity}

The dextrose agar plates were prepared and inoculated with a fungal culture. Wells of approximately $10 \mathrm{~mm}$ was bored using a well cutter and samples of different concentration were added. The zone of inhibition was measured in millimetres after overnight incubation and compared with that of standard antifungal (Fluconazole) $(10 \mu \mathrm{l})$ which was used as positive control and DMSO $(10 \%)$ as the negative control [14].

\section{RESULTS}

The present systematic examination shows the phytochemical analysis, antimicrobial activity of the methanolic extract of the peel of the fruit of Citrus limon. The yield \% of the extraction of methanol was $18.05 \%$. It was dark brown solid powder in appearance.

\section{Phytochemical analysis}

The phytochemical analysis with the methanolic extracts of the dried fruit of plant Citrus limon showed the presence of alkaloids, saponin, sterols, Steroids, terpenoids, protein and amino acid, tannins, carbohydrate are given in (table 1).

\section{Antimicrobial activity}

Generally, Plant extracts are rich in antimicrobial compounds. The in vitro antimicrobial study of the methanolic extracts of fruits peel of Citrus limon under different concentration with the standard are mentioned in (table 2). The methanolic extracts of dried fruits peel of the plant Citrus limon showed antimicrobial activity against most of the test organisms.

Table 1: Phytochemical screening of methanolic extract of dried fruits peel of Citrus limon (family-Rutaceae)

\begin{tabular}{llll}
\hline S. No. & Phytochemical test & Reagent used (test performed) & Observation \\
\hline 1 & Alkaloids test & Mayer's test & Frothing observed \\
& & Wagner's test Dragendroff's test & Turbidity obtained \\
3 & Saponin test & Foam test & Golden yellow colour observed \\
4 & Flavonoid test & Lead acetate test & Yellow colour observed \\
& Carbohydrate test & Molisch's test & \\
& & Benedict's test & Brownish black ppt not observed \\
6 & Glycoside test & Fehling's test & Ring not formed \\
7 & Steroid test & Modified Borntrager's & Gelatin test \\
8 & Tannins test & Salkowski's test & Reddish black not seen \\
\hline
\end{tabular}

+sign indicates the presence and-sign indicates absence. 
Table 2: Antimicrobial activity methanolic extract of dried fruits peel of Cirtuslimon (family-Rutaceae) using disc diffusion assay

\begin{tabular}{|c|c|c|c|c|}
\hline \multirow[t]{2}{*}{$\begin{array}{l}\text { Name of the compounds and their } \\
\text { concentration }\end{array}$} & \multicolumn{2}{|c|}{$\begin{array}{l}\text { Antibacterial activity diameter of inhibition } \\
\text { zone (mm) }\end{array}$} & \multicolumn{2}{|c|}{$\begin{array}{l}\text { Antifungal activity diameter of inhibition } \\
\text { zone (mm) }\end{array}$} \\
\hline & Staphylococcus aureus & Escherichia coli & C. albicans & Trichophyton rubrum \\
\hline Standard Ciprofloxacin $(20 \mu \mathrm{l})$ & 41 & 39 & - & - \\
\hline Standard Fluconazole $(20 \mu \mathrm{l})$ & _- & _- & 31.5 & 30.1 \\
\hline Plant extract $(25 \mu l)$ & 13.5 & 10.2 & 10.3 & 9.8 \\
\hline Plant extract $(50 \mu l)$ & 18.35 & 15.60 & 16.5 & 10.8 \\
\hline Plant extract $(100 \mu \mathrm{l})^{*}$ & 20.6 & 19.5 & 22.2 & 17.5 \\
\hline
\end{tabular}

*significant activity

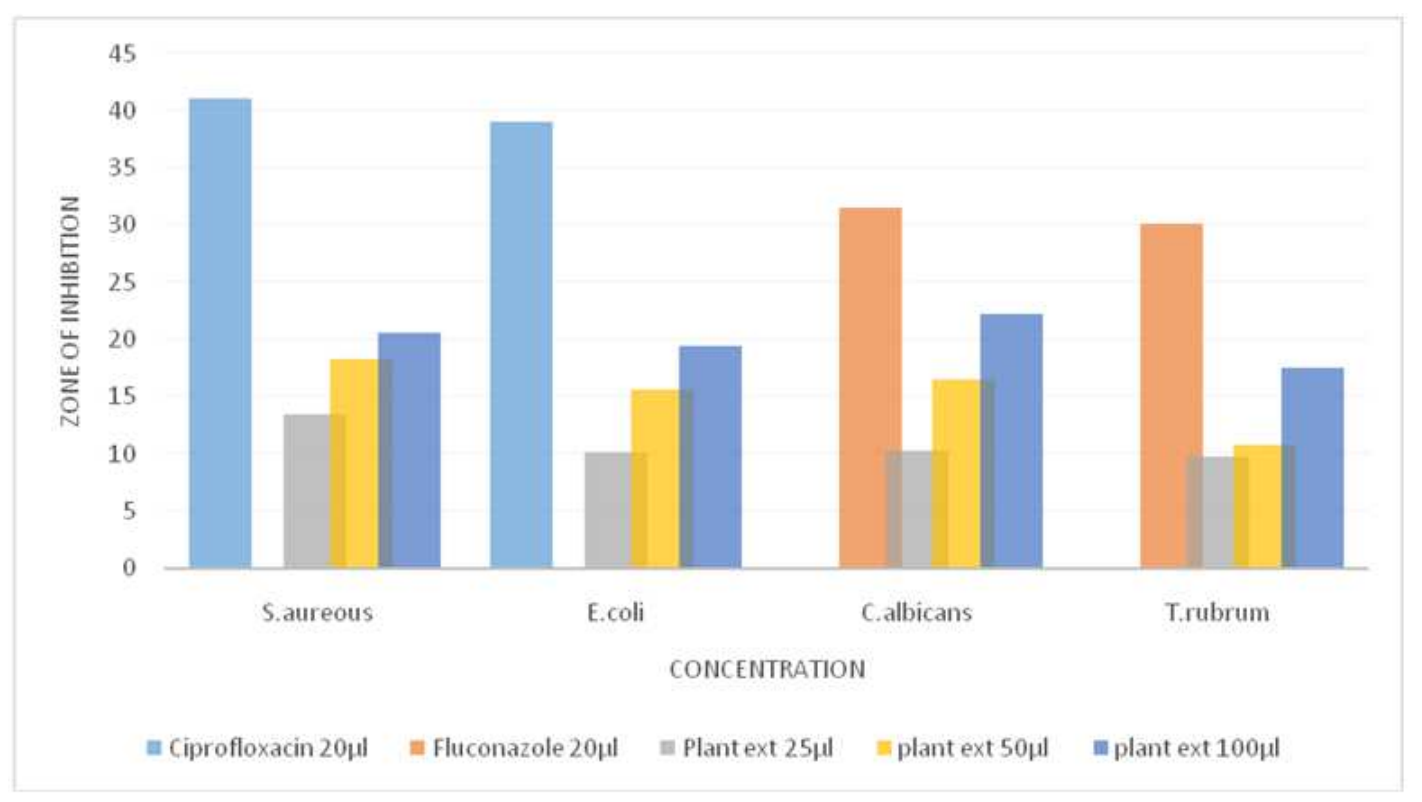

Fig. 1: Zone of inhibition vs concentration

\section{DISCUSSION}

Antimicrobial activity of dried fruits peel of Citrus limon has been evaluated. Phyto-constituents present in plants namely alkaloids, saponin, sterols, terpenoids are having an exciting set of circumstances that makes it possible to do something for more extensive of modern therapies against a wide range of microorganisms. The present study was done against the variety of Gram-positive, Gram-negative bacteria, and fungal strains were selected for screening antimicrobial impact of the extracts to see the antimicrobial spectrum. Results of this study shows that the methanolic extracts of the peel of the fruit of Citrus limon were highly successful in producing the desired result against most of the Gram-positive bacteria, Gram-negative bacteria, and fungal strains in agar well diffusion method.

Phytochemical constituents of plants such as tannins, alkaloids, flavonoids, phenolic compounds and several other aromatic compounds are secondary metabolites which can be used in achieving a defence mechanism against plundering by many micro-organisms.

The practical exhibition and explanation of antimicrobial activity against both Gram-positive and Gram-negative bacteria and on various fungal strains may be an indication of something presence of broad spectrum antibiotic compounds in the extracts which is shown in fig. 3. The $100 \mu \mathrm{g} / \mathrm{ml}$ concentration of dried fruits peel of Citrus limon have an influencing antimicrobial activity.

\section{CONCLUSION}

Medicinal Plant in plant kingdom are the important source of drug and plays a great role for the health of individual and communities. Many plants have been tested for the presence of compounds with therapeutic activity. Therefore, it is absolutely necessary to evaluate the antimicrobial activity of fruits peel of Citrus limon.
From the study, the antibacterial activity of the peel of the dried fruit of Citrus limon was judged by using disk diffusion method. The microorganisms that have been selected for study were Grampositive, S. aureus and Gram-negative E. coli and fungus like $C$. albicans, and T. rubrum. Study of this micro-organism was done as they have the capacity of rapidly developed antibiotic resistance as antibiotic use increases.

After doing the study of a methanolic extract of Citrus limon peel showed the presence of various phytochemicals of which include alkaloids, saponin, sterols, Steroids, and terpenoids.

Tt the end of the conclusion we know about the significant antimicrobial activity of the plant extracts when estimated with standards. So, after lots test, decision and thoughts it was found that the minimum inhibitory concentration of the plant extracts was less than $100 \mu \mathrm{g} / \mathrm{ml}$ and therefore the plant was considered to have a very good antimicrobial activity.

However, further studies are definitely required to put light on the unknown biological activities of Citrus lemon peel and its effect on living organisms, tissues or cells against various diseases.

\section{CONFLICT OF INTERESTS}

Declare none

\section{REFERENCES}

1. Nada KK, Zainab AGC. Antimicrobial activity of different aqueous lemon extracts. J Appl Pharm Sci 2013;3:74-8.

2. Behboud J, Amirreza K. Antibacterial activities methanol of extract and lemongrass essence on pathogenic bacteria. World Appl Sci J 2013;28:1796-801. 
3. Velu S, Abu Bakar F, Mahyudin NA, Saari N, Zaman MZ. In vitro antimicrobial activity of musk lime, in vitro antimicrobial activity of musk lime. Int Food Res J 2014;12;379-86.

4. Maruti J, Dhanavade CB, Jalkute JS, Ghosh Kailash DS. Study antimicrobial activity of lemon. Br J Pharmacol Toxicol 2011;2:119-22.

5. Akhilesh K, Raghvendra P, Vikas S, Madhulika G. Antimicrobial property of lemon peel extract. Natl J Universal Pharm Life Sci 2012;52:382-6.

6. Amit P, Arti K, Sudeep KT. Evaluation of antimicrobial activity and phytochemical analysis of Citrus limon. J Pharm Biomed Sci 2011;13:101-7.

7. Mohanapriya M, Rajender R. Health and medical property of lemon. Int J Ayurvedic Herbal Med 2013;3:1095-100.

8. Brant LJ. Intestinal microbiota and the role of fecal microbiota transplant in the treatment of C. difficile infection. Am J Gastroenterol Lecture 2013;108:177-85.

9. Gulsen 0, Roose ML. Lemons diversity and relationships with selected citrus genotypes as measured with nuclear genome markers. J Am Soc Horticultural Sci 2001; 126:309-17.

10. Wainwright M. Moulids in ancient and more recent medicine. Mycologist 2003;3:21-3.

11. Kingston W. Irish contributions to the origins of antibiotics. Irish J Med Sci 2008;177:87-92.

12. Julia M. Lemon in fruits of warm climates."Purdue University"; 1987. p. $160-8$

13. Koehn FE, Carter GT. The evolving role of natural products in drug discovery. Nat Rev Drug Discovery 2014;2:379-86.

14. http://www.businessdictionary.com/definition/pathogens.ht $\mathrm{ml}$. [Last accessed on 20 Dec 2016].

15. Parta AK. Dietary phytochemicals. Publisher spirzyeer; 2008. p. 301-6.

\section{How to cite this article}

- Junab Ali, Biswajit Das, Trideep Saikia. Antimicrobial activity of lemon peel (Citrus limon) extract. Int J Curr Pharm Res 2017;9(4):79-82. 